\title{
Sıcak iklim değişiklikleri çocuklarda nefrolitiazis riskini arttırır mı?
}

\section{Does warm climate increases risk of nephrolithiasis in children?}

Rahime Renda

Antalya Eğitim ve Araştırma Hastanesi, Çocuk Nefroloji Bölümü, Antalya, Türkiye

\section{ÖZ}

Amaç: Çocuklarda nefrolitiazis oluşumunda çevresel, genetik risk faktörleri ile metabolik bozuklukların de yer aldığı ve sıklığı gittikçe artan bir hastalık grubudur. En sık saptanan metabolik bozukluklar hiperkalsiüri ve hipositratüridir. Çalışmamızın amacı, Akdeniz bölgesindeki pediatrik yaş grubunda nefrolitiazisli hastaların başvuru tarihleri, demografik, metabolik ve klinik özelliklerini değerlendirerek risk faktörlerini belirlemektir.

Gereç ve Yöntem: Ocak 2015 ile Mart 2018 arasında hastanemiz çocuk nefroloji polikliniğinde nefrolitiazis tanısı almış 129 hasta (55 kız,74 erkek) çalışmaya alındı. Bu hastaların başvuru tarihleri, demografik parametreleri, klinik semptomları, metabolik ve radyolojik tetkikleri retrospektif olarak incelendi.

Bulgular: Toplam 129 hasta, 55’i kız $(\% 42,6)$ ve 74 'ü erkek $(\% 57,4)$, yaş ortalaması 4,2 $\pm 4,7$ yıl idi. Hastaların \%71,3'ünde tek taraflı, \%24,8'inde ise iki taraflı renal yerleşimli taş saptandı. En sık görülen klinik semptom huzursuzluk, renal kolik ve hematüri idi. Metabolik değerlendirmeler incelendiğinde hastaların 39'unda hiperürikozüri, 29'unda hiperkalsiüri, 14'ünde hipositratüri ve hiperoksalüri, üçünde sistinüri saptandı. İdrar yolu enfeksiyonu 23 hastada tespit edilirken, 15 hastaya medikal tedaviye ek olarak cerrahi tedavi gerekli görüldü. Geliş tarihleri incelendiğinde hastaların büyük kısmının (\%67,4'ü) sıcak mevsimlerde (ilkbahar ve yaz) başvurduğu ve tanı aldığı saptandı.

Sonuç: Sıcak iklimde yaşamanın, dehidratasyon nedeniyle böbrek taşı oluşma riskini arttırdığını düşünmekteyiz. Sıvı alımının yetersiz olması, infant grubunda, böbrek taşlarının büyümesini destekleyen idrar ürik asit ve kalsiyumun yüksek atılımına yol açmaktadır.

Anahtar Sözcükler: Çocuk, nefrolitiazis, risk faktör, mevsim.

\section{ABSTRACT}

Aim: Children are an increasingly prevalent group of diseases in which environmental, genetic risk factors and metabolic disorders are associated in the formation of nephrolithiasis. The most prevalent metabolic abnormalities are hypocitraturia and hypercalciuria. The aim of our study is to assess the risk factors by determining the application dates, demographic, metabolic and clinical features of nephrolithiasis patients in the pediatric age group in the Mediterranean region.

Materials and Methods: We evaluated the clinical, radiological, laboratory findings and metabolic parameters of 129 children (74 boys and 55 girls) with nephrolithiasis between January 2015 and March 2018, retrospectively. Application dates of patients, symptoms, urinary infection, metabolic disturbances, radiological findings and treatment modalities were determined.

Results: A total of 129 patients, 55 (42.6\%) were female and 74 (57.4\%) were male, the mean age was $4.2 \pm 4.7$ years. $71.3 \%$ of the patients had unilateral and $24,8 \%$ of the patients had bilateral renal stones.

Sorumlu yazar: Rahime Renda

Antalya Eğitim ve Araştırma Hastanesi, Çocuk Nefroloji

Bölümü, Antalya, Türkiye

E-posta: rahimeg@yahoo.com

Başvuru tarihi: 06.02.2020

Kabul tarihi: 01.09.2020 
The most common clinical symptom was restlessness, renal colic and hematuria. When the metabolic evaluations were examined, 39 patients had hyperuricosuria, 29 had hypercalciuria, 14 had hypocitraturia and hyperoxaluria, and 3 had cystinuria. While urinary tract infection was detected in 23 patients, surgical treatment was required in addition to medical treatment in 15 patients. When the dates of arrival were investigated, it was found that most of the patients (67.4\%) were admitted and diagnosed to the warm seasons (spring and summer).

Conclusion: We think that living in warm climates increase the risk of harboring kidney stones due to dehydration, which leads to a high excretion of urinary calcium and other minerals that promote the growth of kidney stones.

Keywords: Child, nephrolithiasis, risk factor, season.

\section{GiRiş}

Çocukluk çağı taş hastalığı, özellikle infantil yaşlarda insidansı giderek artan, uzun dönemde son dönem böbrek yetmezliğine neden olabilen önemli bir klinik problemdir $(1,2)$. Nefrolitiazis sıklığındaki artış; diyet alışkanlığında değişiklik, obezitenin son yıllarda artması, ultrasonografinin rutin kullanımının yaygınlaşmış olması ve farkındalığın artması ile ilişkili olabilir.

Genel olarak çocuklarda nefrolitiazis görülme oranı \%2-3 olmakla birlikte, infantlarda bu oran \%9-23'e kadar çıkmaktadır (3-6). Taş oluşumunu etkileyen risk faktörler; altta yatan hastalıklar (konjenital anormali/metabolik bozukluk), sosyoekonomik nedenler, genetik ve iklimsel faktörler olabilir $(7,8)$.

Hematüri ve renal kolik gibi semptomlar adölesan ve erişkinde sık görülürken, küçük çocuk ve infantlarda ise kilo alamama, kusma, iştahsızlık, huzursuzluk gibi nonspesifik semptomlar daha sık görülmektedir $(4,9,10)$. Erken teşhis ve tedavi çocukluk çağında ileri dönemde oluşabilecek kalıcı renal hasarın önlenmesi açısından oldukça önemlidir. Bu çalışmada çocuk nefroloji polikliniğine başvuran ve nefrolitiazis tanısı alan hastaların geliş ve başvuru sırasındaki tarih belirlenerek mevsimlerle ilişkisini ortaya koymak, demografik verileri, semptomları, risk faktörleri, uygulanan tedavi yöntemlerininin de retrospektif olarak incelenmesi amaçlanmıştır.

\section{GEREÇ ve YÖNTEM}

Ocak 2015 ile Mart 2018 tarihleri arasında hastanemiz Çocuk Nefroloji Polikliniği'ne başvuran ve nefrolitiazis tanısı alan 129 hastanın verileri retrospektif olarak değerlendirildi. Çalışmamız Helsinki Deklarasyonu'nun kılavuz ilkelerine uygun olarak yapıldı ve hastanemiz Etik Kurul (9/1-03/05/2018) tarafından onaylandı. Yazılı hasta onamı hastalar veya ebeveynleri tarafından alındı.
Radyolojik olarak taşı gösterilen, endoskopik veya açık cerrahi ile taşı alınan veya spontan taş düşmesi olan hastalar çalışmaya alındı. Hastaların dosyaları retrospektif olarak taranarak yaş, cinsiyet, semptom, klinik bulgular, metabolik analizler, radyolojik bulgular ve taş analizleri incelendi. Cerrahi olarak taşı çıkarılan veya taş düşüren hastaların taş analizleri özel laboratuvarlarda yapıldı. Tüm hastaların metabolik incelemeleri yapıldı. Büyük çocuklarda 24 saatlik idrarda ürik asit, kalsiyum, sitrat, okzalat ve sistin miktarları ölçüldü. Küçük hastalarda ise analizler spot idrardan yapıldı. Hiperkalsiüri tanısı, infant ve küçük çocuklarda spot idrar/kalsiyum oranının yaşa uygun olarak yüksek bulunması, büyük çocuklarda ise 24 saatlik idrarda kalsiyum atılımının $4 \mathrm{mg} / \mathrm{kg} / \mathrm{gün}$ 'den fazla olması ile konuldu (8, 11, 12). Hiperürikozüri yaşa göre belirlenen ürik asit/kreatinin oranının standartların üzerinde olması veya günde $>815 \mathrm{mg} / 1,73 \mathrm{~m} 2$ olması ile tanımlandı. Hipositratüri günlük sitrat atılımının $<140 \mathrm{mg} / 1,73 \mathrm{~m} 2$ veya 5 yaşından küçüklerde sitrat/kreatinin oranının $<0,42 \mathrm{mg} / \mathrm{mg}, 5$ yaşından büyük olanlarda ise $<0,25 \mathrm{mg} / \mathrm{mg}$ olması ile tanımlandı. Hiperoksalüri için yaşa göre oksalat/kreatinin değerinin yüksek olması veya 24 saatlik idrarda $>45 \mathrm{mg} / 1,73 \mathrm{~m} 2 /$ gün olması ile tanı konuldu (13-17). Sistinüri tanısı Nitropurissid testi pozitifliği ve idrar amino asit kromotografisinde sistin yüksekliği, idrar mikroskopisinde sistin kristallerinin görülmesi ile konuldu. Bu vakalarda sistinozis ayırıcı tanısı için lökosit içi sistin düzeyi çalışıldı. Sistinürili hastalarda tiopronin, sistinozisli vakalarda ise sisteamin tedavisi başlandı ve metabolizma bölümü tarafından da izleme alındı (18). Tüm hastalara sodyumdan kısıtlı diyet önerildi ve sıvı alımı arttırıldı. İlaç olarak hiperkalsiürik olup sodyum kısıtlaması ile düzelmeyenlere hidroklorotiazid (1-2mg/kg), hipositratürik olgulara oral potasyum sitrat $(1-2 \mathrm{mEq} / \mathrm{kg})$ verildi. 
Hiperoksalürisi olanlara oksalattan fakir diyet ve piridoksin tedavisi başlandı. Üriner sistem enfeksiyonu olanlara kültür sonuçlarına uygun tedavi verildi ve sık tekrarlayanlar profilaksiye alındı. Ayrıca hastaların geliş ve ilk başvuru tarihleri incelenerek, mevsimlere göre sayı ve yüzde dağılımları yapıldı.

\section{İstatiksel Analiz}

Tüm veriler SPSS 22.0 sürümü (IMB SPSS Inc., New York, Amerika Birleşik Devletleri) kullanılarak analiz edildi. Sürekli sayısal değişkenler ortalama \pm standart sapma olarak, kategorik değişkenler sayı ve yüzde olarak özetlenmiştir. Sürekli sayısal değişkenlerin dağılıma uyup uyumadığını tespiti için Shapiro Wilk Testi kullanıldı.

\section{BULGULAR}

Toplam 129 hasta, 55'i kız $(\% 42,6)$ ve 74'ü erkek $(\% 57,4)$, yaş ortalaması $4,2 \pm 4,7$ yıl, çalışmaya alındı. Tanı sırasında kızların yaş ortalaması $4,2 \pm 4,8$ yıl, erkeklerin $4,1 \pm 4,7$ yıl olarak bulundu. Doksan iki vakada $(\% 71,3)$ taş tek taraflı $(\% 46,5$ $n=60$ solda; \%24,8- $n=32$ sağda), $32(\% 24,8)$ hastada ise iki taraflı renal yerleşimli taş saptandı (Tablo-1). Hastaların başvuru sırasındaki şikayetleri incelendiğinde sırasıyla en sık huzursuzluk, renal kolik ve hematüri tespit edildi. Diğer nedenlerle (ishal, gelişme geriliği, idrar yolu enfeksiyonu vb.) ilişkili yapılan USG'lerde 28 $(\% 21,7)$ hastada renal taş görüldü (Tablo-2). (Tablo-3)'te hastaların incelenen metabolik parametre sonuçları verilmektedir. En sık görülen metabolik bozukluk hiperürikozüri ve hiperkalsiüri iken, $26(\% 18,6)$ hastada ise metabolik değerlendirme sonuçları normal bulundu. Sistinüri saptanan üç olgunun yapılan ileri tetkiklerinde bir hastaya sistinozis tanısı konuldu.

Incelenen laboratuvar parametrelerinde hastaların 20 'sinde $(\% 15,5)$ fosfor yüksekliği, üç hastada $(\% 2,3)$ kalsiyum yüksekliği, iki hastada $(\% 1,6)$ magnezyum yüksekliği, bir hastada $(\% 0,8)$ magnezyum düşüklüğü, 19 hastada da $(\% 14,7)$ 25-Dvit düzeyi düşük bulundu. Hastaların hiçbirinde $D$ vitamini yüksekliği ve hiperparatiroidi saptanmadı. Hastalardan alınan hikâye ve tam idrar tetkik sonuçları değerlendirildiğinde 23 hastada $(\% 17,8)$ üriner sistem enfeksiyonu, bunların 11 tanesinde de tekrarlayan üriner sistem enfeksiyonu tespit edildi.
Ultrasonda taşların boyutları incelendiğinde, en sık olarak 3-5 mm büyüklüğünde taşlar saptandı. Bir hastada renal taş obstrüksiyonuna bağlı akut böbrek yetmezliği gelişti. Ancak taşın cerrahi olarak çıkarılmasından sonra böbrek fonksiyon testleri normale döndü. Hastaların büyük çoğunluğu konservatif (sıvı alımı+diyet) ve medikal tedavi ile takip edilirken, 15 hastada $(\% 11,6)$ ek olarak cerrahi tedavi uygulandı (Tablo-4). Takipte hastaların hiçbirinde kronik böbrek hasarı gelişmedi.

Hastaların geliş ve ilk başvuru tarihleri incelendiğinde hastaların 87'si $(\% 67,4)$ oldukça sıcak mevsim olan ilkbahar -yaz, 42'sinin $(\% 32,6)$ ise sonbahar-kış mevsiminde geldiği ve tanı aldığı görüldü (Şekil-1).

Tablo-1. Üriner ultrasonda taş lokalizasyonu.

\begin{tabular}{lc}
\hline Taşın yeri & Sayı (\%) \\
\hline Böbrek (Tek tarafı/çift taraflı) & $113(67.3) / 48(28.6)$ \\
Üreter & $6(3.5)$ \\
Böbrek ve üreter & $1(0.6)$ \\
\hline
\end{tabular}

Tablo-2. Hastaların başvuru şikayetleri.

\begin{tabular}{lcc}
\hline Semptom & Hasta sayısı (n) & Yüzde (\%) \\
\hline Hematüri & 23 & 17,8 \\
Huzursuzluk & 34 & 26,4 \\
Karın ağrısı & 15 & 11,6 \\
Renal kolik & 29 & 22,5 \\
Rastlantısal & 28 & 21,7 \\
\hline
\end{tabular}

Tablo-3. Patolojik metabolik parametreler,

\begin{tabular}{lc}
\hline Patolojik Bulgular & Sayı (\%) \\
\hline Hiperkalsiüri & $29(20.7)$ \\
Hiperürikozüri & $39(27.9)$ \\
Hiperkalsiüri+hiperürikozüri & $11(7.9)$ \\
Hipositratüri & $14(10)$ \\
Hiperkalsiüri+hipositratüri & $2(1.4)$ \\
Hiperokzalüri & $14(10)$ \\
Sistinüri & $3(2.1)$ \\
Normal & $26(18.6)$ \\
Struvit taşı & $1(0.7)$ \\
Kalsiyum oksalat+ürik asit taşı & $1(0.7)$ \\
\hline
\end{tabular}


Tablo-4. Taş boyutu ve izlem sonuçları.

\begin{tabular}{|c|c|c|}
\hline Taş boyutu & Sayı(\%) & Lokalizasyon \\
\hline & & 23 tane sol bb \\
\hline \multirow[t]{3}{*}{$<3 \mathrm{~mm}$} & $39(23,2)$ & 5 tane sağ bb \\
\hline & & 11 tane iki bb \\
\hline & & 30 tane sol bb \\
\hline \multirow[t]{4}{*}{$3-5 m m$} & $73(43,5)$ & 17 tane sağ bb \\
\hline & & 23 tane iki bb \\
\hline & & 3 tane üreter \\
\hline & & 17 tane sol bb \\
\hline \multirow[t]{4}{*}{$>5 \mathrm{~mm}$} & $56(33,3)$ & 22 tane sağ bb \\
\hline & & 14 tane iki bb \\
\hline & & 3 tane üreter \\
\hline & & 70 tane sol bb \\
\hline \multirow[t]{3}{*}{ Toplam } & $168(100)$ & 44 tane sağ bb \\
\hline & & 48 tane iki bb \\
\hline & & 6 tane üreter \\
\hline \multicolumn{3}{|l|}{ İzlem } \\
\hline Konservatif & $53(41.1)$ & \\
\hline Medikal & $61(47.3)$ & \\
\hline Cerrahi & $6(4.6)$ & \\
\hline Medikal+cerrahi & $9(7)$ & \\
\hline
\end{tabular}

*bb: börek

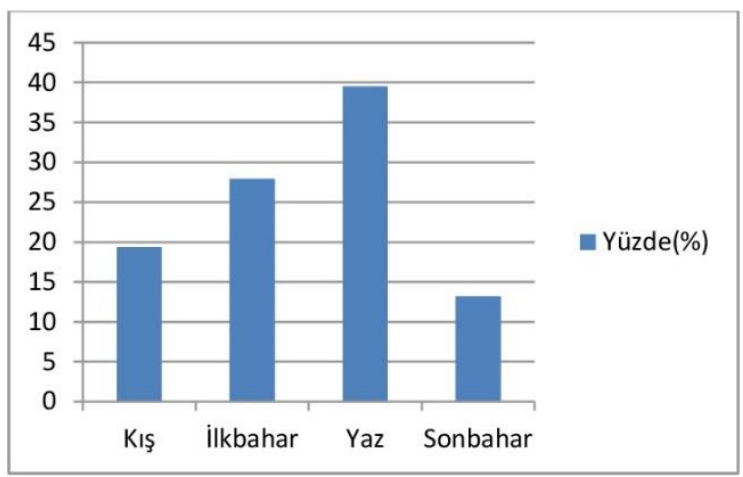

Şekil-1. Mevsimlere göre hasta başvuru yüzdeleri.

\section{TARTIŞMA}

Üriner sistem taş hastalığı, özellikle sıcak iklim olan bölgelerde daha sık görülen, çocukluk çağında kronik böbrek yetmezliğine de yol açabilen yaygın bir hastalıktır $(19,20)$. Özellikle son yıllarda ülkemizde ve dünyada infant döneminde nefrolitiazis sıklığı $\operatorname{artmıştır~}(1,2,21)$. Ülkemizden yapılan iki çalışmada infant dönemi üriner sistem taş hastalığı sırasıyla $\% 34$ ve $\% 41$ olarak bildirilmiştir $(4,9)$. Bu artışta nonspesifik semptomlarda bile USG ve idrar bakısının yapılmasının artışı ile birlikte, formül mama kullanımının artması da önemli bir faktördür (18). Metabolik nedenlere bağlı taşın en sık görüldüğü ülkeler Pakistan, Türkiye, Afrika iken İngiltere ve Avrupa ülkelerinde daha çok enfeksiyona bağlı taşlar (struvit) görülmektedir (22). Cinsiyete göre taş sıklığına bakıldığında ülkemizde ve birçok Asya ülkesinde erkeklerde daha sık görülürken, Amerika'da acil servise gelen vakalarda kız erkek oranı benzer bulunmuştur (18, 23-25). Bizim çalışmamız da ülkemizden yapılan diğer çalışmalarla uyumlu olarak erkek insidansı yüksek bulunmuştur,

Çalışmamızda tanı alma yaşlarına bakıldığında kız ve erkeklerde benzer oranlar saptanmıştır. Dinçel ve arkadaşları ile Baysal ve arkadaşları yaptıkları çalışmalarda erkek çocuklarının tanı alma yaşı kızlarınkinden küçük bulmuşlardır (18, 26). Bir başka çalışmada da tanı sırasında bulunan tanı yaşı bizim hastalarımızdan küçüktür (5). Bu farklılıklar, coğrafi bölge ve iklim farklııkları, diyet ve şüphe dahilinde yapılan tanısal testlerin bölgesel dağılımına bağlanabilir.

Birçok çalışmada, hastalarda en sık görülen başvuru semptomu karın ağrısı ve renal kolik olarak bulunmuştur (23). Literatürde makroskopik veya mikroskobik hematüri sıklığı \%33-90 arasında değişmektedir (27). Bizim çalışmamızda hematüri daha düşük oranda $(\% 17,8)$ saptanmış olup, en sık başvuru semptomu huzursuzluk ve renal kolik olarak tespit edilmiştir. Bunun nedeni olarak hasta semptomlarının yaşa bağlı olarak değişmesinden kaynaklanmaktadır. Büyük çocuklarda karın ağrısı ve renal kolik daha sık görülürken, infant ve süt çocuğu döneminde huzursuzluk gibi nonspesifik semptomlar daha ön plandadır. Ayrıca küçük çocuklarda diğer sebeplere bağlı yapılan USG oranı da yüksek olduğundan, rastlantısal saptanan taş oranı da bu dönemde artmaktadır. Bizim çalışmamızda infant ve süt çocuğu sayısı fazla olduğundan huzursuzluk semptomu ve rastlantısal nedenlere bağlı nefrolitiazis sıklığı fazla bulunmuştur.

Çocukluk çağı nefrolitiazis oluşumunda \%75-85 oranında altta yatan bir risk faktörü vardır (28). Metabolik bozukluklar, üriner sistem enfeksiyonu ve konjenital anomaliler bunlardan bazılarıdır (5, 29). İnhibitör maddelerin idrardaki yoğunluğunun 
azalması (sitrat, pirofosfat) veya taş oluşumunu kolaylaştırıcı maddelerin (kalsiyum, oksalat, sistin) idrardaki yoğunluğunun artması ile metabolik taşlar oluşur $(10,21)$. İnfant ve küçük çocuk taş hastalığında yüksek oranda (\%52-85) bir veya birkaç metabolik bozukluk bulunmuştur $(4,9,30)$. Yapılan çalışmaların çoğunluğunda en sık görülen metabolik bozukluk hiperkalsiüri, infantlarda ise hiperkalsiüri ve hiperürikozüridir $(4,9)$. Türkiye'den yapılan çalışmaların bazılarında hipositratüri en sık görülen metabolik bozukluk olarak tespit edilmiştir $(31,32)$. Çalışmamızda, diğer çalışmalarla uyumlu olarak hiperkalsiüri ve hiperürikozüri en sık saptanan metabolik bozukluk olup, üçüncü sırada hipositratüri ve hiperoksalüri gelmektedir. Hiperoksalüri infantlarda \%3-43 oranlarında saptanmış olup, diyetle fazla alımla birlikte çocuklarda oksalatın enterik malbsorbsiyonuna bağlı da gelişebilir $(4,9)$. Sistinüriye bağlı taş oluşumu diğer çalışmalarla uyumlu olarak oldukça düşük oranda bulunmuştur $(6,30)$. Özellikle rekkürens gösteren taşlarda metabolik nedenler araştırılarak erken tedaviye başlamanın kronik böbrek hasarını önlediği bilinmektedir. Çalışmamızda taş boyutu, USG'de en sık 3-5 mm arasında saptanmış olup, diğer çalışmalara benzer şekilde yoğunluk üst üriner sistemde görülmüştür $(18,25)$. Laboratuvar bulgularında serum fosfat, kalsiyum ve magnezyum yüksekliği özellikle hazır mama ile beslenen bebeklerde yüksek bulunmuştur. Taşlı hastalarda üriner sistem enfeksiyonunun arttığı çalışmalarla gösterilmiş olup, bizim çalışmamızda da $\% 17,8$ hastada tespit edilmiştir $(22,25)$.

Taşın kimyasal yapısı ile mevsimler arasında ilişki olup olmadığını araştıran az sayıda çalışma mevcuttur, Çalışmalar daha çok erişkinde yapılmış olup, farklı sonuçlar elde edilmiştir.
Malta adasında yapılan bir çalışmada, taş oluşumu ve mevsimler arasında ilişki bulunamaz iken, Güney Avustralya'da yapılan diğer bir çalışmada, ürik asit taşlarının daha çok yaz mevsiminde, infeksiyon taşlarının da ilkbahar ve yazın daha çok görüldüğü rapor edilmiştir (19, 33). Amerika'da yüksek sıcaklıklarda özellikle kalsiyum oksalat ve ürik asit taşlarının arttığı bildirilirken, Brezilya'da ise sıcak mevsimlerin barsak florasını etkileyerek hipositratüriye neden olduğu gösterilmiştir $(34,35)$. Antalya şehri, Akdeniz ikliminin etkisinde olup, ilkbahar ve yaz mevsimleri oldukça sıcak nemli geçmektedir. Özellikle bu aylarda infant ve küçük çocuklar yeterli sıvı alamadıkları takdirde çok daha kolay dehidrate kalabilmektedirler. Bu da idrardaki solüt miktarının artmasına ve taş oluşumuna zemin hazırlamaktadır (21). Bizim çalışmamız da sıcak mevsimlerde, anne sütü ile beslenen ve yeterli sıvı alamayan infant ve küçük çocuklarda hiperürikozürinin ve hiperkalsiürinin ortaya çıkabileceğini göstermiştir. Bu nedenle, sıcak iklimin baskın olduğu bölgelerde, erken dönemde sıvı alımının artııılması önleyici tedavinin temelini oluşturmaktadır.

\section{SONUÇ}

Çocuklarda taş hastalığı son yıllarda özellikle infantlarda sıklığı artan ve böbrek yetmezliğine de neden olabilen önemli bir sağlık sorunudur. Sıcak iklimde yaşam; dehidratasyon ve ürik asit ile kalsiyum atılımını arttırarak böbrek taşı oluşumunu kolaylaştırmaktadır.

Çıkar çatışması: Yazarlar arasında "Çıkar çatışması" bulunmamaktadır.

\section{Teşekkür}

Yayın yazımı sırasında istatistik analiz yapımında yardımlarından dolayı Prof. Dr. Mehmet Ziya Fırat hocamıza teşekkür ederim.

\section{Kaynaklar}

1. Clayton DB, Pope JC. The increasing pediatric stone disease problem. Ther Adv Urol 2011; 3: 3-12.

2. Sas DJ, Hulsey TC, Shatat IF, Orak JK. Increasing incidence of kidney stones in children evaluated in the emergency department. J Pediatr 2010; 157, 132-7.

3. Spivacow FR, Negri AL, del Valle EE, Calvino I, Fradinger E, Zanchetta JR, Metabolic risk factors in children with kidney stone disease, Pediatr Nephrol, 2008; 23: 1129-33.

4. Baştuğ $F$, Gündüz Z, Tülpar $S$, Poyrazoğlu $H$, Düşünsel $R$, Urolithiasis in infants: evaluation of risk factors, World J Urol 2013; 31: 1117-22.

5. Coward RJ, Peters CJ, Duffy PG, Corry D, Kellett MJ, Choong S, et al, Epidemiology of paediatric renal stone disease in the UK, Arch Dis Child 2003; 88: 962-5.

6. Dursun I, Poyrazoglu HM, Dusunsel R, Gunduz Z, Gurgoze MK, Demirci D, et al. Pediatric urolithiasis: an 8year experience of single centre, Int Urol Nephrol 2008; 40: 3-9. 
7. Elder JS, Urinary lithiasis, In: Behrman RE, Kliegman RM, Jenson HB, Stanton BF, editors. Nelson textbook of pediatrics, 18th ed. Philadelphia: Saunders; 2008; 2267-72.

8. Milliner DS, Urolithiasis, In: Avner ED, Harmon WE, Niaudet P, Pediatric nephrology, 5th ed, Philadelphia: Springer; 2009; p, 1405-1431.

9. Alpay H, Gokce I, Ozen A, Bıyıklı N, Urinary stone disease in the first year of life: is it dangerous? Pediatr Surg Int 2013; 29: 311-316.

10. Baştuğ $F$, Düşünsel R, Pediatric urolithiasis: causative factors, diagnosis and medical management, Nat Rev Urol 2012; 9: 138-146.

11. Choi H, Synder HM, 3rd, Duckett JW, Urolithiasis in childhood: current management, J Pediatr Surg 1987; 22 : 158-164,

12. Miller LA,Stapleton FB, Urinary volume in children with urolithiasis, J Urol 1989;141: 918-920.

13. Hoppe B, Leumann E, Milliner DS, Urolithiasis and nephrocalcinosis in childhood, In: Geary DF, Schaefer F (eds), Comprehensive Pediatric Nephrology, 1st edn, Mosby, Philadelphia, PA, 2008; 499-526.

14. Poyrazoğlu HM, Düşünsel R, Yazici C, Durmaz H, Dursun I, Sahin H, et al, Urinary uric acid: creatinine ratios in healthy Turkish children, Pediatr Int 2009; 51: 526-529.

15. Matos V, Van Melle G, Werner D, Bardy D, Guignard JP, Urinary oxalate and urate to creatinine ratios in a healthy pediatric population, Am J Kidney Dis 1999; 34:e1.

16. Matos V, Van Melle G, Boulat O, Markert M, Bachmann C, Guignard JP, Urinary phosphate/creatinine, calcium/ creatinine, and magnesium/creatinine ratios in a healthy pediatric population, $J$ Pediatr 1997;131:252-257.

17. Habbig S, Beck BB, Hoppe B, Nephrocalcinosis and urolithiasis in children, Kidney Int 2011; 80: 1278-1291,

18. Dinçel N, Özdemir K, Mir S, Demographic and Clinic Features of Children with Nephrolithiasis in Izmir, J Cont Med, 2012; 2: 77-81.

19. Buttigieg J, Attard S, Carachi A, Galea R, Fava S, Nephrolithiasis, stone composition, meteorology, and seasons in Malta: Is there any connection? Urol Ann 2016; 8: 325-332,

20. Sirohi M, Katz BF, Moreira DM, Dinlenc C, Monthly variations in urolithiasis presentations and their association with meteorologic factors in New York City, J Endourol 2014; 28: 599604.

21. Baştuğ F, İnfantlarda Üriner Sistem Taş Hastalı̆ı: Etyoloji ve Tedavi, Endoüroloji Bülteni 2013; 6: 143-151,

22. Gillespie RS, Stapleton FB, Nephrolithiasis in Children, Pediatr Rev 2004; 25: 131-139.

23. Afshin Safaei Asl, Shohreh Maleknejad, Pediatric Urolithiasis An Experience of a Single Center, Iranian Journal of Kidney Diseases 2011; 5: 309-313.

24. Tiselius HG, Ackermann D, Alken P, Working Party on Lithiasis: European Association of Urology Guidelines on urolithiasis, Eur Urol 2001; 40: 362-71.

25. Sternberg K, Greenfield SP, Williot P, Wan J, Pediatric stone disease: an evolving experience, J Urol 2005; 174: $1711-1714$.

26. Baysal YE, Koyun M, Akman S, Güven AG, Güntekin E, Çocuklarda ürolitiyazis: Antalya yöresinde 10 yıllık deneyim, Çoc Sağ ve Hast Der 2004; 47: 254-259.

27. Türk C, Knoll T, Petrik A, Sarica K, Straub M, Seitz C, Guidelines on urolithiasis, Working Party on Lithiasis, European Association of Urology, 2012.

28. Dursun İ, Ünsür EK, Çocuklarda üriner sistem taş hastalığına güncel yaklaşım, Çoc Cer Der 2016; 30: 146-155.

29. Miyake O, Yoshimura K, Yoshioka T, Koide T, Okuyama A, High urinary excretion level of citrate and magnesium in children: potential etiology for the reduced incidence of pediatric urolithiasis, Urol Res 1998; 26: 209.

30. Alpay H, Ozen A, Gokce I, Biyikli N, Clinical and metabolic features of urolithiasis and microlithiasis in children, Pediatr Nephrol 2009; 24: 2203-2209.

31. Tekin A, Tekgul S, Atsu N, Bakkaloglu M, Kendi S, Oral potassium citrate treatment for idiopathic hypocitruria in children with calcium urolithiasis, J Urol 2002;168:2572-2574.

32. Tekin A, Tekgul S, Atsu N, Sahin A, Ozen H, Bakkaloglu M, A study of the etiology of idiopathic calcium urolithiasis in children: hypocitruria is the most important risk factor, J Urol 2000;164:162-165.

33. Baker PW, Coyle P, Bais R, Rofe AM, Influence of season, age, and sex on renal stone formation in South Australia, Med J Aust 1993;159:390392.

34. Eisner BH, Sheth S, Herrick B, Pais VM Jr, Sawyer M, Miller N, et al, The effects of ambient temperature, humidity and season of year on urine composition in patients with nephrolithiasis, BJU Int 2012;110:10141017.

35. Atan L, Andreoni C, Ortiz V, Silva EK, Pitta R, Atan F, et al, High kidney stone risk in men working in steel industry at hot temperatures, Urol 2005; 65: 858861. 